\title{
Formação de professores indígenas numa perspectiva intercultural
}

\section{Indigenous teacher training within an intercultural perspective}

\author{
Claudia Pereira Antunes* \\ Maria Aparecida Bergamaschi**
}

\begin{abstract}
Resumo: O presente artigo trata da formação de professores indígenas tendo como cenário as ações que envolvem docentes, lideranças Kaingang e gestores dessa política no Estado do Rio Grande do Sul. O foco central do trabalho que aqui apresentamos e sobre o qual aprofundamos a reflexão é o Curso de Especialização em Educação Profissional Integrada à Educação Básica na Modalidade Educação de Jovens e Adultos - Proposta diferenciada para Indígenas, realizado na Universidade Federal do Rio Grande do Sul com financiamento da Secretaria de Educação Profissional e Tecnológica do Ministério da Educação. Os estudos, que são vinculados à pesquisa "Educação Ameríndia e Interculturalidade", possibilitam a compreensão desse curso de especialização no contexto mais amplo da formação de professores indígenas e da educação escolar indígena.
\end{abstract}

Palavras-chave: Formação de professores indígenas. Educação escolar indígena. Educação intercultural.

\begin{abstract}
Current analysis discusses indigenous teacher training foregrounded on the activities that involve teachers, Kaingang chiefs and government officials responsible for this policy in the state of Rio Grande do Sul, Brazil. The Specialization Course in Professional Education integrated to Fundamental Education, within the modality Education for Young People and Adults - A differentiated proposal for Amerindians, is the main objective of current study. The course is run by the Federal University of Rio Grande do Sul and funded by the Secretary for Professional Education and Technology of the Brazilian Ministry of Education. Studies related to the research 'Amerindian Education and Interculturality' underlie the above-mentioned specialization course within a wider context of the formation of indigenous teachers and indigene school education.
\end{abstract}

Keywords: Indigenous teacher training. Indigenous school education. Intercultural education.

\footnotetext{
* Técnica em Assuntos Educacionais da Universidade Federal do Rio Grande do Sul e Mestre em Educação pela mesma universidade. E-mail: <claudia.antunes.poa@gmail.com>

** Docente da Faculdade de Educação da Universidade Federal do Rio Grande do Sul. E-mail: <cida.bergamaschi@gmail.com>
} 


\section{Introdução}

Este trabalho, escrito a quatro mãos, apresenta reflexões iniciais propiciadas pelo Curso de Especialização em Educação Profissional Integrada à Educação Básica na Modalidade Educação de Jovens e Adultos - Proposta diferenciada para Indígenas, realizado na Universidade Federal do Rio Grande do Sul, com financiamento da Secretaria de Educação Profissional e Tecnológica do Ministério da Educação, nos anos de 2011/2012. O contexto que permite compreender esse curso no âmbito da educação escolar indígena advém das ações e reflexões vinculadas à pesquisa "Educação Ameríndia e Interculturalidade", que agrega estudos tanto nas escolas indígenas como nas escolas não indígenas e na academia, buscando identificar, compreender e subsidiar espaços e processos que envolvem a educação, a escola e os saberes ameríndios na universidade, especialmente considerando a presença de estudantes indígenas nos cursos de graduação e pós-graduação. Em especial, agrega estudos advindos de uma pesquisa de mestrado que analisa as experiências e os desafios para uma educação escolar diferenciada a partir da formação específica de professores indígenas no Rio Grande do Sul.

Para compreender os movimentos que configuram a formação de professores indígenas, principalmente considerando um curso de Especialização em pleno andamento no qual nos vemos envolvidas, buscamos apreendê-lo por meio da construção de uma cartografia ${ }^{2}$ que ao mesmo tempo acompanha o processo, registra-o e o produz. Em especial, valemo-nos de uma perspectiva etnográfica que se aproxima do "contorno antropológico", formulado por Balandier (1997, p. 18-19) como recurso metodológico para guiar e empreender um avanço para o desconhecido em movimento. Neste sentido, o contorno antropológico efetua uma ação no próprio movimento que se anuncia, criando um "exotismo interior, o estranho (exôtikos) não mais recebido do exterior, de espaços culturais diferentes, mas composto de elementos já existentes e vindos de um certo futuro próximo e gerador do novo", como "preparação a uma ação cognitiva que permite uma compreensão tanto pelo interior (o pesquisador se identifica para conhecer) quanto pelo exterior (o pesquisador vê em função de uma experiência estranha)". Concordando com Balandier (1997, p. 19), buscamos "dar inteligibilidade ao que se esconde dos sistemas das interpretações comumente utilizados", para compreender os processos de formação de professores indígenas nos quais participamos. Essa perspectiva possibilita

\footnotetext{
${ }^{1}$ Projeto de pesquisa coordenado pela Professora Dra. Maria Aparecida Bergamaschi, registrado em 2011 no portal de pesquisas da UFRGS sob o número 20357 e financiado pelo CNPq, processo n. ${ }^{\circ}$ 470726/2011-3.

${ }^{2}$ Rolnik (1989) diz que elaborar uma cartografia permite, a um só tempo, acompanhar e produzir. Afinadas com a autora, pensamos na cartografia como processualidade que, enquanto demarca, enquanto desenha uma trajetória, nela intervém, mudando a paisagem.
} 
acompanhar o movimento, constituir espaços onde caibam inquietações e indagações e constituir uma ordem, precária e efêmera, que acolha a desordem de processos em um pujante e complexo movimento, de múltiplas e cambiantes significações, sem capturá-los em definições que se encerram em pretensas certezas. Contextualizando por aproximação aquilo que se sabe, inventa-se uma cartografia, buscando os possíveis, traçando outros itinerários e identificando novas configurações e sua interpretação (DORNELES, 2003, p. 4-5).

O curso de Especialização, que compõe a centralidade deste estudo, configura a primeira formação específica para professores indígenas em nível de pós-graduação lato sensu, envolvendo educadores do povo Kaingang ${ }^{3}$, docentes universitários e gestores da educação do Ministério da Educação e da Secretaria de Estado da Educação do Rio Grande do Sul. Para melhor compreendê-lo, contextualizamos a formação de professores indígenas na história recente da educação escolar e, na sequência, detalhamos os antecedentes próximos, dos quais decorrem o planejamento do curso, sua configuração como uma formação acadêmica institucional, os diálogos e os atores envolvidos nesse movimento intercultural; e por fim, apresentamos o que chamamos de um "ensaio etnográfico sobre o PROEJA Indígena na UFRGS", ou seja, o registro que cria o "exotismo interior" e permite sua compreensão tanto pelo interior quanto pelo exterior. Concluímos o trabalho elencando algumas indagações e constatações suscitadas nesse processo que configuram conquistas, desafios e possibilidades para a formação intercultural.

\section{Contextualização}

Há cem anos, quando havia sido recentemente criado o Serviço de Proteção aos Índios e Localização de Trabalhadores Nacionais (SPILTN), mais tarde apenas SPI, as expectativas de seus idealizadores eram de integração dos povos indígenas à sociedade nacional. De acordo com seu decreto de criação, o SPI poderia intervir "com brandura", consultando as lideranças indígenas, para modificar hábitos e práticas das comunidades indígenas na prestação de assistência a estas. $\mathrm{O}$ decreto também previa a criação de escolas para instrução primária sem caráter obrigatório, proibindo que se coagisse "os índios e seus filhos a qualquer ensino ou aprendizagem, devendo limitar-se a ação do inspetor e de seus auxiliares a procurar convencê-los, por meios brandos, dessa necessidade" (BRASIL, 1910, Art. 15). Essa crença na integração dos povos indígenas predominou na política indigenista até o final do século XX, tendo resistido à substituição do SPI pela Fundação Nacional do Índio (FUNAI)

\footnotetext{
${ }^{3}$ Povo Indígena do sul do Brasil, pertencente à família macro-jê, conforma na atualidade uma das maiores populações indígenas do país.
} 
na década de 1960 e à criação do Estatuto do Índio, na década seguinte. Esse Estatuto, criado em 1973, tem o propósito ambíguo de preservar a cultura dos povos indígenas e integrá-los à sociedade nacional, destinando à escola o papel de promover essa integração (BRASIL, 1973).

Contrariando essas expectativas, ao final da década de 1980 a nova Constituição Federal rompe com a política de integração das comunidades indígenas e reconhece pela primeira vez seu direito às formas de organização social, usos e costumes tradicionais e o direito a educação específica e diferenciada. Essa mudança foi conduzida com a participação dos movimentos indígenas articulados no processo constituinte e abriu caminho para outros referenciais legais relativos à educação indígena pautados pela interculturalidade, entre os quais as Diretrizes para a Política Nacional de Educação Escolar Indígena, de 1993, que, ao afirmar que a educação escolar indígena deve ser intercultural e bilíngue, específica e diferenciada, demarca as diferenças entre o projeto atual de educação indígena e o anterior (BRASIL, 1994).

Em 1996, a Lei de Diretrizes e Bases da Educação Nacional, Lei n. ${ }^{\circ}$ 9.394, reitera os preceitos constitucionais e em 1998 é lançado o Referencial Curricular Nacional para as Escolas Indígenas (RCNEI). Em 1999 a Resolução 03, do Conselho Nacional de Educação, estabelece diretrizes para o funcionamento das escolas indígenas no país, "reconhecendo-lhes a condição de escolas com normas e ordenamento jurídico próprios" (BRASIL, 1999, Art. $\left.1^{\circ}\right)$.

O crescimento demográfico da população indígena, observado no final do século XX e início do XXI, também contraria as expectativas de desaparecimento cultivadas desde a colonização do país e muito propaladas na primeira metade do século XX. De acordo com o IBGE, os resultados do Censo Demográfico 2010 apontam 817 mil pessoas autodeclaradas indígenas, evidenciando um crescimento de 84 mil indígenas entre 2000 e 2010. No período anterior, 1991-2000, o aumento demográfico fora de 440 mil indígenas $^{4}$ (IBGE, 2012, p. 12). O crescimento populacional e as mudanças no marco legal evidenciam a resistência e a força dos povos indígenas, que vêm conquistando cada vez mais espaço na gestão das políticas que os afetam. Dados do Censo Escolar Indígena 1999 e do Censo Escolar 2005 mostram que naqueles anos os números de alunos matriculados em escolas indígenas do Rio Grande do Sul eram,

\footnotetext{
${ }^{4}$ Conforme relatório do IBGE, para o crescimento da população indígena no período de 1991/2000 "Não existe nenhum efeito demográfico que explique tal fenômeno. Muitos demógrafos atribuíram o fato a um momento mais apropriado para os indígenas, em que estavam saindo da invisibilidade pela busca de melhores condições de vida, mais especificamente, os incentivos governamentais." (IBGE, 2012, p. 4). De toda forma, os dados evidenciam a expressividade do contingente populacional indígena e contrariam a ideia de declínio populacional vigente no século XX.
} 
respectivamente, de 3.057 e 4.365 alunos (BRASIL, 2001, 2007). Em 2010 já havia 5.417 estudantes matriculados em 48 escolas indígenas estaduais e três municipais, sendo que quatro atendiam a etnia Guarani. No decurso de uma década o número de matrículas em escolas indígenas quase dobrou.

Os professores indígenas também conquistaram espaço com a mudança de orientação da política indigenista, em decorrência da Constituição Federal. Em 1999, nas escolas indígenas do país, 76,5\% dos professores eram indígenas ${ }^{5}$ e em 2007 o MEC estimou que este percentual aumentou para 90\% ${ }^{6}$. Para o Rio Grande do Sul, dados do Censo Escolar Indígena de 1999 apontam que naquele ano havia 89 professores das etnias Kaingang e Guarani nas escolas indígenas do estado, representando 37,2\% dos docentes dessas escolas; já no ano de 2002, atuavam nas escolas indígenas do estado mais de 200 professores indígenas, representando aproximadamente $70 \%$ do corpo docente dessas escolas ${ }^{7}$.

As conquistas legais e de espaços nas políticas públicas e em especial na educação escolar se deram com a participação ativa das comunidades indígenas nas lutas pelos seus direitos, desde a década de 1980. No Rio Grande do Sul, em 1991 foi criada a Associação dos Professores Bilíngues Kaingang e Guarani - APBKG, com o propósito de ser um "instrumento de luta pela oferta e garantia do ensino diferenciado e de qualidade" para os povos indígenas (BELFORT, 2005, p. 16). De acordo com a professora Kaingang Andila Belfort, fundadora da APBKG, os primeiros professores indígenas tinham status de monitores e foram contratados pela FUNAI em meados da década de 1970, por meio de uma portaria coletiva que nomeou monitores para os estados do Sul (Paraná, Rio Grande do Sul e Santa Catarina). Eram 19 concluintes do Primeiro Curso de Formação de Monitores Indígenas Bilíngues do país, realizado na Terra Indígena de Guarita, no Rio Grande do Sul. Desde então os monitores passaram a lutar por espaço nas escolas indígenas (BELFORT, 2005, p. 13-15). A sua contratação pela FUNAI também possibilitou o despertar para os limites do ensino ministrado nas escolas indígenas: se por um lado contribuíam para a valorização da língua indígena, por outro, estavam "a serviço da desintegração cultural" de seu povo (BELFORT, 2005, p. 13-15).

\footnotetext{
${ }^{5}$ Censo Escolar Indígena 1999.

${ }^{6}$ Estatísticas de Educação Escolar Indígena do Brasil. (BRASIL, 2007).

${ }^{7}$ Banco de Dados das Escolas Estaduais Indígenas, Departamento Pedagógico da Secretaria Estadual de Educação. Dados referentes a julho de 2002. (RIO GRANDE DO SUL, 2002a).
} 
A regularização das escolas indígenas no estado iniciou em 1992, com o primeiro processo de transferência de escola indígena para a Secretaria de Educação (RIO GRANDE DO SUL, 2002b). Tal transferência efetivou-se em 1995 (BERGAMASCHI, 2005). Em 1996 foi celebrado um convênio entre o Estado do Rio Grande do Sul e a FUNAI, por meio do qual esta cedia à Secretaria os imóveis e benfeitorias de escolas repassadas ao estado; contudo, a transferência da maioria das escolas sob responsabilidade da FUNAI para o estado só se concretizou no ano de 2002. O Ofício-Circular do Gabinete do Departamento Pedagógico da SEE N 39 , de 03 de julho de 2001, que estabeleceu os procedimentos para a regularização das escolas localizadas em terras indígenas, lista 21 escolas com portaria de criação da FUNAI que deveriam ser assumidas pelo estado (RIO GRANDE DO SUL, 2001). Essas escolas, juntamente com outras 20 estaduais e municipais, tiveram seus decretos de criação como escolas estaduais indígenas assinados em 2002. Dados da $\mathrm{SEE}^{8}$ mostram que, entre as escolas em funcionamento no ano 2000, a mais antiga entrou em funcionamento em 1931: a Escola Estadual Indígena de Ensino Fundamental Retánh Leopoldino, na Terra Indígena de Monte Caseros, município de Muliterno, para atender alunos da etnia Kaingang. Até o final da década de 1980, 24 escolas indígenas entraram em funcionamento no estado, 11 só na década de 1960; e outras 13 começaram a funcionar na década de 1990.

Em decorrência das responsabilidades assumidas com a educação escolar indígena, em especial a partir da Resolução CNE 03/1999 (BRASIL, 1999), a qual estabelece que os professores das escolas devem ser prioritariamente indígenas e têm direito à formação em serviço. Considerando o perfil de formação dos professores indígenas do estado, no ano de 2000 a SEE estabeleceu critérios diferenciados para a contratação emergencial de professores indígenas, permitindo a contratação de docentes que estivessem cursando o Ensino Fundamental para atuarem nas séries iniciais do Ensino Fundamental. No ano de 2002 havia 198 professores indígenas contratados emergencialmente atuando nas escolas indígenas sendo 45 deles nas séries finais do Ensino Fundamental ${ }^{9}$. De acordo com os dados da tabela a seguir, em 1999, mais de um terço dos 89 professores indígenas que atuavam nas escolas indígenas tinham formação em nível de ensino fundamental, completa ou incompleta, e quase um terço tinha formação em Magistério Indígena, sendo que apenas 8 professores tinham formação em nível superior.

\footnotetext{
${ }^{8}$ Dados extraídos do quadro de dados das escolas indígenas no RS - 2000, da Divisão de Estrutura e Funcionamento Escolar, da SEE. (RIO GRANDE DO SUL, 2000).

${ }^{9}$ Banco de Dados das Escolas Estaduais Indígenas, da SEE, dados referentes a julho de 2002. (RIO GRANDE DO SUL, 2002a).
} 
Tabela 1 - Nível de formação dos professores indígenas no Rio Grande do Sul em 1999

\begin{tabular}{l|c|c}
\hline \multicolumn{1}{c|}{ Nível de formação } & Professores indígenas & $\begin{array}{c}\text { Professores indígenas e } \\
\text { não indígenas }\end{array}$ \\
\hline Fundamental Incompleto & 12 & 12 \\
\hline Fundamental Completo & 29 & 33 \\
\hline Médio - Magistério Completo & 7 & 87 \\
\hline Médio - Magistério Indígena & 28 & 41 \\
\hline $\begin{array}{l}\text { Médio - outra formação } \\
\text { completa }\end{array}$ & 10 & 29 \\
\hline Superior com Magistério & 6 & 13 \\
\hline Superior sem Magistério & 2 & $\mathbf{2 3 9}$ \\
\hline Total Censo & $\mathbf{8 9}$ & 28 \\
\hline
\end{tabular}

Fonte: Censo Escolar Indígena, 1999.

Buscando consolidar as transformações necessárias à escola diferenciada, em 2001 a SEE realizou pela primeira vez um concurso para os cargos de Professor de Ensino Fundamental - Séries Iniciais: quatro primeiras séries em língua kaingang e Professor de Ensino Fundamental - Séries Iniciais, e quatro primeiras séries em Língua Portuguesa, com conhecimentos em Língua kaingang. Dos 32 inscritos, 20 foram aprovados e nomeados, aí incluídos dois professores não indígenas. No âmbito da formação inicial de professores indígenas, em 2001 foi criada a Escola Estadual Indígena de Ensino Médio de Formação de Professores Kaingang Bilíngues, porém tal iniciativa se concretizou ao final de uma gestão e duas outras se seguiram sem que a escola fosse inaugurada. Em julho de 2010, o Ministério Público Federal, em Santo Ângelo, acionou a Secretaria Estadual, solicitando que a escola, cujas instalações físicas foram concluídas em 2004 entrasse em funcionamento ${ }^{10}$.

As mudanças na educação escolar indígena no final do século XX criaram a demanda de professores indígenas, assim como demandas de cursos específicos para esses professores. No Rio Grande do Sul, após a Constituição de 1988 essa demanda passou a ser atendida por meio de diferentes iniciativas que, juntas, formaram cerca de cem alunos.

A seguir, apresentamos ${ }^{11}$ um breve histórico dos cursos de formação específica de professores indígenas.

\footnotetext{
${ }^{10}$ Notícias - Site do Ministério Público Federal. Disponível em: <http://noticias.pgr.mpf.gov.br/noticias/ noticias-do-site/copy_of_indios-e-minorias/mpf-rs-quer-instalacao-de-escola-de-formacao-de-professoresindigenas $>$.

${ }^{11}$ Esses dados, de forma mais completa, constam no projeto de dissertação "A formação específica de professores indígenas no Rio Grande do Sul: experiências e desafios para uma educação escolar diferenciada", apresentado ao Programa de Pós-Graduação em Educação da UFRGS em junho de 2011 pela mestranda Claudia Pereira Antunes.
} 


\section{Cursos de formação específica de professores indígenas no Rio Grande do Sul}

O histórico da formação específica de professores indígenas no Rio Grande do Sul é descontínuo e se constitui de diferentes iniciativas, com a participação das comunidades indígenas e de instituições de ensino de cunho indigenista que promoveram formações pontuais até o momento. Como demonstrado anteriormente, em 1970 foi implantada a primeira turma do curso de Formação de Monitores Bilíngues, Projeto Clara Camarão, coordenado pela FUNAI e pelo Summer Institute of Linguistics (SIL). O curso intencionava formar profissionais Kaingang e Guarani para auxiliarem no trabalho dos professores não indígenas impossibilitados pela falta de domínio do idioma, no processo de alfabetização das crianças indígenas. A sua proposta pedagógica estava afinada com o projeto político vigente na época, que visava à integração dos povos indígenas à sociedade nacional. Embora o curso intencionasse a formação dos monitores para atuarem como auxiliares na escolarização das crianças indígenas com o propósito claro de modificar seus modos de vida e integrá-las à "comunhão nacional", aqueles encontraram nessa formação um espaço de valorização da língua indígena. Naquele momento a FUNAI "não apostou nos índios como professores. Mesmo assim, o efeito foi de potencialização do idioma de cada etnia, fortalecendo lideranças jovens [...]" (BERGAMASCHI, 2005, p. 184).

Os cursos posteriores foram todos realizados após a promulgação da Constituição Federal de 1988 e se desenvolveram num marco legal de reconhecimento à educação intercultural, específica e diferenciada e de valorização dos professores indígenas. Neste sentido, a Portaria Interministerial 559/1991 determinava que os docentes que atuassem na educação indígena tivessem capacitação específica para trabalhar nas comunidades, e que fossem executados programas de formação permanente, tendo o professor indígena prioridade nesses programas (BRASIL, 1991a). Outros documentos legais também surgiriam no sentido de balizar a formação dos professores indígenas, entre eles a Resolução 03/1999 (BRASIL, 1999), que garante aos professores a sua formação em serviço, e os Referenciais para a Formação de Professores Indígenas, de 2002, que expressa a necessidade de um processo de formação permanente que permita aos professores indígenas cursar o ensino superior, e a necessidade de instâncias administrativas que viabilizem esse processo de formação e a participação dos professores indígenas no processo educacional.

Dessa forma, no Rio Grande do Sul, no período de 1993 a 1996, o segundo curso de formação específica para professores indígenas no estado, desenvolvido na modalidade supletivo em nível de Ensino Médio, formou 22 professores indígenas, e apenas cinco anos depois houve nova iniciativa neste sentido, com 
o Projeto Vãfy, que formou cerca de 80 professores Kaingang em $2005^{12}$. Entre 2004 e 2010 desenvolveu-se a primeira experiência específica de formação de professores Guarani com caráter inter-regional, envolvendo estados do Sul e Sudeste. Também está em andamento o curso de Licenciatura Intercultural Indígena do Sul da Mata Atlântica na Universidade Federal de Santa Catarina (UFSC), onde há 27 estudantes do RS (22 da etnia Kaingang e cinco da etnia Guarani $\left.^{13}\right)$. O curso também disponibilizou vagas para estudantes da etnia Xokleng, 40 para cada etnia, 120 no total.

Abaixo estão relacionados os cinco cursos de formação específica em nível de Ensino Médio que habilitam professores indígenas para atuação nas séries iniciais do ensino fundamental.

Projeto Clara Camarão (1970 a 1980) - 1a , $2^{\mathrm{a}}$ e $3^{\mathrm{a}}$ turmas

O Projeto Escola Normal Indígena Clara Camarão (ENICC) posteriormente denominado Centro de Treinamento Profissional Clara Camarão (CTPCC), foi promovido pela FUNAI e pelo SIL, num período em que esse instituto assumiu a responsabilidade pelos programas educacionais da FUNAI (COLLET, 2003, p. 174). O curso iniciou suas atividades no ano de 1970 e formou três turmas de monitores bilíngues até o ano de 1980 (AMANCIO, 2000). O centro de treinamento localizava-se no município de Tenente Portela, Terra Indígena de Guarita.

Este curso foi marcado por um grande rigor disciplinar, conforme relato da professora Andila Inácio Belfort, aluna da primeira turma, que narra o regime de internato, destacando a violência praticada contra os costumes Kaingang, a repressão às conversas entre os estudantes e os castigos aplicados pela desobediência (BELFORT, 2005). A primeira turma de monitores bilíngues Kaingang formou-se em 1972 e dela fizeram parte dezenove professores indígenas dos estados do Rio Grande do Sul, Santa Catarina e Paraná, sendo três Guarani e os demais Kaingang.

Curso Supletivo de Formação de Professores Indígenas Bilíngues - Segundo Grau - Habilitação Magistério - 1993-1996

Este curso foi promovido pela Universidade Regional do Noroeste do Estado do Rio Grande do Sul (UNIJUÍ), com apoio da APBKG, da Organização das Nações Indígenas do Sul (ONISUL), do Conselho de Missão entre Índios (COMIN), vinculado à Igreja Evangélica de Confissão Luterana do Brasil (IECLB), do Conselho Indigenista Missionário (CIMI), vinculado à Igreja Católica, da Secretaria Estadual de Educação e do Ministério da Educação. O

\footnotetext{
${ }^{12}$ Dado apresentado por Bruno Ferreira em comunicação pessoal.

${ }^{13}$ Dado apresentado por Rodrigo Venzon em comunicação pessoal.
} 
seu objetivo era formar professores Kaingang para o ensino de primeira a quarta séries das escolas indígenas do RS e SC. As aulas iniciaram em 1993 e foram realizadas em regime intensivo nos meses de janeiro, fevereiro e julho, totalizando 2.400 horas, no município gaúcho de Bom Progresso. Em 1996 formaram-se no curso 22 professores indígenas habilitados para trabalhar no ensino de primeira a quarta séries.

Projeto Vãfy (Artesanato - idioma Kaingang) - Curso de Formação de Professores Kaingang ou Guarani para o Magistério em Educação Escolar Indígena - Anos iniciais do Ensino Fundamental (2001-2005)

O Projeto Vãfy foi criado a partir de um convênio entre a Universidade de Passo Fundo (UPF), e a FUNAI. Desenvolvido com apoio da UNIJUí (Universidade Regional do Noroeste do Estado do Rio Grande do Sul) e do FIDENE (Fundo de Integração, Desenvolvimento e Educação do Noroeste do Estado), realizou-se nos municípios de Redentora, Terra Indígena de Guarita e Benjamin Constant do Sul, Terra Indígena de Votouro, entre os anos de 2001 e 2005. O curso foi direcionado para os professores Kaingang que atuavam nas escolas indígenas, objetivando atender à demanda de formação específica para atuação nas escolas indígenas. Formou-se em torno de 80 professores habilitados para o ensino de primeira a quarta série nas escolas indígenas ${ }^{14}$. De acordo com o projeto pedagógico do curso, este seria desenvolvido em regime especial, com $30 \%$ da carga horária na forma de atividades em serviço desenvolvidas nas escolas das comunidades de origem dos alunos ${ }^{15}$.

Programa de Formação para Professores Guarani das Regiões Sul e Sudeste Kuaa Mbo'e - Conhecer/Ensinar (2004-2009)

Este curso foi criado a partir do Protocolo de Intenções celebrado em 2004 pelas Secretarias de Estado de Educação dos Estados de Santa Catarina, Rio Grande do Sul, Paraná, Rio de Janeiro e Espírito Santo, pelo Ministério da Educação e pela Fundação Nacional do Índio (FUNAI), e objetivou a formação de professores Guarani em nível de Ensino Médio, com habilitação para o ensino nas séries iniciais do Ensino Fundamental. Esta foi a primeira experiência de formação específica de professores Guarani na perspectiva etnoterritorial. Sua articulação foi iniciada por professores da Universidade Federal de Santa Catarina e por organizações indigenistas, entre elas a Comissão de Apoio aos Povos Indígenas (CAPI), as quais a partir do ano de 2001 promoveram encontros entre representantes das secretarias estaduais de educação e professores Guarani para planejar o curso. Seus conteúdos curriculares estavam organizados em três

\footnotetext{
${ }^{14}$ Dado informado por Bruno Ferreira em comunicação pessoal.

${ }^{15}$ Esses cursos de formação de professores, cuja incidência envolveu uma maioria de professores kaingang estão sendo estudados em profundidade e comporão a dissertação de Mestrado de Claudia Pereira Antunes.
} 
partes: 1) Base Comum - Língua Guarani, Língua Portuguesa e Literatura, Artes, Geografia, História e Organização Social Guarani, Antropologia, Sociologia, Ciências (Física, Química, Biologia e Saúde Pública) e Matemática; 2) Parte Diversificada - questões específicas da cultura Guarani por eixos temáticos; e 3) Parte Profissionalizante - Metodologia de Ensino e Pesquisa, Didática, Fundamentos (Psicologia, Sociologia, Filosofia e História da Educação) e Legislação da Educação.

Curso de Especialização em Educação Profissional Integrada à Educação Básica na Modalidade Educação de Jovens e Adultos - Proposta diferenciada para Indígenas

O Curso de Especialização foi destinado, num primeiro momento, a estudantes Kaingang, Guarani ${ }^{16}$ e Xokcleng ${ }^{17}$, bem como a lideranças, gestores e mediadores das políticas de educação escolar indígena. O referido curso foi planejado visando à formação de profissionais das sociedades indígenas com capacidades para atuar na elaboração de estratégias e na provisão de condições necessárias para processos de educação escolar profissional e básica, específica e diferenciada articulados aos saberes e aos modos de vida da tradição. Também visa à participação dos profissionais indígenas como autores na construção de políticas públicas e propostas educacionais próprias.

A proposição de um curso diferenciado, que considere as especificidades étnicas, as cosmologias próprias e as características comunitárias dos grupos participantes, atende a uma demanda nacional no que tange a leis que orientam a educação escolar indígena e contempla a necessidade de formar profissionais destes grupos sociais, que historicamente foram relegados dos processos de educação formal, mas neste momento, vislumbram a possibilidade de protagonizar ações de ensino diferenciadas, que valorizem e fortaleçam suas histórias e suas culturas e, consequentemente, as suas comunidades.

A iniciativa de um curso de pós-graduação lato sensu específico para indígenas foi gestada no seio do programa de especialização PROEJA ${ }^{18}$ desenvolvido pela Universidade Federal do Rio Grande do Sul em parceria com

\footnotetext{
${ }^{16}$ Devido ao pequeno número de estudantes guarani com graduação completa, o curso foi realizado majoritariamente por alunos pertencentes ao povo Kaingang. Dos 25 matriculados, um pertencia ao povo guarani e, após a primeira etapa desistiu do curso, permanecendo, então, unicamente estudantes indígenas Kaingang (entre estes três desistiram), além de um grupo de não indígenas (entre os quais dois desistiram), conforme será explicado na sequência.

${ }^{17}$ Inicialmente uma estudante autodeclarada xokcleng iniciou o curso, mas findada a primeira etapa se desligou, sendo que um dos motivos apontados foi a pouca possibilidade de identificação, visto a maioria de alunos Kaingang.

${ }^{18}$ Programa de Educação de Jovens e Adultos Integrado à Educação Profissional, instituído pela Secretaria de Educação Profissional e Tecnológica do Ministério da Educação do Brasil tem, no bojo de suas ações, cursos de especialização - pós-graduação lato sensu, visando a formação de professores. (BRASIL, 2010).
} 
os CEFETs (Centro Federal de Educação Tecnológica) ${ }^{19}$ do Rio Grande do Sul. Desde a segunda edição, o programa abriu vagas específicas para estudantes indígenas e, em decorrência, três professoras Kaingang ${ }^{20}$ concluíram suas monografias e obtiveram o certificado de especialistas. Seus trabalhos finais, já publica$\operatorname{dos}^{21}$, mostram uma produção que evidencia identificações entre as necessidades indígenas e as proposições do PROEJA, qual seja, conjugar a Educação Básica para Jovens e Adultos com a Educação Profissional, esta vinculada a demandas e estratégias específicas das comunidades e dos povos indígenas. Na terceira edição da Especialização PROEJA, seis estudantes Kaingang iniciaram o curso; porém a distância entre a proposta de formação não indígena e as necessidades de educação escolar diferenciada indígena intensificou conflitos e incompreensões, assentadas nas diferenças cosmológicas de sociedades distintas, mostrando a urgência de um curso destinado especificamente aos povos originários. Dos seis ingressantes indígenas da terceira edição, apenas um elaborou trabalho monográfico, também resultando em publicação ${ }^{22}$.

Em inúmeros depoimentos os estudantes indígenas que realizavam o curso mencionavam a necessidade de uma especialização específica, sonho que foi acalentado, transformado em projeto e encaminhado à Secretaria de Educação Profissional e Tecnológica do Ministério da Educação, que, após detalhada e prolongada análise, dispôs-se a financiá-lo com o aval acadêmico da Pró-Reitoria de Pós-Graduação da Universidade Federal do Rio Grande do Sul. A participação das três primeiras estudantes Kaingang da especialização na elaboração do projeto foi fundamental, pois estas souberam apontar elementos necessários para a configuração da proposta de Especialização em Educação Profissional Integrada à Educação Básica na Modalidade Educação de Jovens e Adultos - Proposta Diferenciada para Indígenas.

É também importante ressaltar que há a presença de estudantes nos cursos de graduação da UFRGS desde 2008, a partir de uma resolução do Conselho Universitário $^{23}$ que criou um programa específico de acesso e permanência de dez estudantes indígenas a cada ano. Essa política se alia a um movimento nacional de crescimento intensivo de estudantes ameríndios no Ensino Superior. Segundo Baniwa e Hoffmann (2010), no final da primeira década do século XXI somamse seis mil estudantes indígenas em universidades brasileiras, basicamente em duas modalidades: 1) as licenciaturas ou os cursos interculturais específicos e diferenciados,

\footnotetext{
${ }^{19}$ Esses centros foram transformados posteriormente em Institutos Federais de Educação - IFEs.

${ }^{20}$ Andila Nĩvygsãnh Inácio; Maria Inês de Freitas e Márcia Gojtẽn Nascimento.

${ }^{21}$ Bergamaschi e Venzon (2010).

${ }^{22}$ Claudino (2010).

${ }^{23}$ Trata-se da decisão n ${ }^{\mathbf{0}}$ 134/2007 que, em seu artigo 12, estabelece: "No ano de 2008, serão disponibilizadas 10 vagas para estudantes indígenas cuja forma de distribuição será definida pelo CEPE, ouvidas as comunidades indígenas e a COMGRAD dos cursos demandados. A partir do ano de 2009 este número de vagas poderá ser alterado” (UNIVERSIDADE FEDERAL DO RIO GRANDE DO SUL, 2007).
} 
que atendem principalmente a uma demanda de formação de professores e gestores ambientais; e 2) as políticas que reservam ou criam vagas específicas nos cursos já existentes em instituições de ensino superior, como é o caso da UFRGS, que no ano de 2012 consolida a presença de 42 estudantes em várias graduações, sendo que treze deles estão cursando licenciaturas ${ }^{24}$. Segundo os mesmos autores, há uma presença significativa de estudantes indígenas também em mestrados e doutorados em diversas universidades brasileiras, dado que mostra a necessidade concreta e atual de os povos originários estabelecerem um diálogo próximo com a academia.

O curso de especialização, na modalidade que explicitaremos aqui, vem ao encontro dos movimentos empreendidos por lideranças indígenas e destinase aos que já possuem formação superior, especialmente a licenciados, e entre estes, prioritariamente, professores indígenas que atuem nas escolas estaduais indígenas situadas em terras indígenas, bem como, profissionais indígenas da área da saúde que atuem junto à Secretaria de Saúde Indígena (SESAI). O curso também previu vagas para técnicos da Secretaria de Estado da Educação do Rio Grande do Sul que atuam como gestores nas coordenadorias regionais onde se situam as escolas indígenas. A partir de um levantamento prévio de possíveis candidatos para a especialização, foram planejadas 35 vagas, das quais 25 para estudantes indígenas e 10, de forma complementar, destinadas aos profissionais da educação que atuam diretamente com as políticas educacionais indígenas, indicados pelas comunidades a quem o curso se destina.

Antes do início do curso, alguns movimentos constituíram o que chamamos de divulgação e seleção: ao mesmo tempo em que mostrávamos o projeto às comunidades indígenas, mapeamos e inscrevemos possíveis candidatos. Foram realizadas palestras visando aproximar a universidade ao universo indígena e dirimir assim a distância histórica entre esses dois mundos. Também se considerou relevante que as comunidades participassem do processo de indicação/ seleção dos participantes do curso, visto que estes profissionais desempenharão um papel destacado na implementação das políticas e práticas educacionais, principalmente das voltadas para cursos específicos e diferenciados que contemplem o ensino profissional e a formação básica. Estas palestras conformaram três momentos/espaços: 1) Terra Indígena Serrinha - Município de Ronda Alta; 2) Terra Indígena Guarita - Município de Tenente Portela; 3) Terra Indígena Por fi - Município de São Leopoldo, Grande Porto Alegre.

A concepção do curso, por um lado seguiu o modelo geral dos cursos de especialização PROEJA, e por outro, abriu a possibilidade para componentes

\footnotetext{
${ }^{24}$ Pedagogia (4); Letras (1); História (4); Educação Física (1); Biologia (2); Ciências Sociais (1). Os demais estudantes indígenas distribuem-se nos cursos de Medicina, Odontologia, Enfermagem, Farmácia, Nutrição, Psicologia, Fisioterapia, Agronomia, engenharia Mecânica, Veterinária, Serviço Social, Psicologia, Direito e Jornalismo.
} 
curriculares - conteúdos e metodologia - que contemplassem necessariamente os modos de vida e os saberes da tradição ameríndia, em especial do povo Kaingang. Considerando o pressuposto de que a educação escolar precisa estar em consonância com a história e a cultura de um povo, de uma comunidade, mas também incorporar saberes e conhecimentos acadêmicos, o Curso de Especialização PROEJA Indígena elegeu como premissa o diálogo dos conhecimentos e saberes tradicionais indígenas e os conhecimentos e saberes acadêmicos. Nesta perspectiva, se considerou: a elaboração de módulos em que as questões específicas indígenas pudessem ser tratadas em suas especificidades; uma base curricular que possibilite a integração dos conhecimentos, buscando uma abordagem interdisciplinar; tempos e espaços de trocas em que as questões indígenas constituam um núcleo comum.

No tocante à organização das horas-aula, o curso foi realizado conforme a pedagogia da alternância ${ }^{25}$, constando de oito semanas de estudos presenciais na universidade, alternados com períodos na comunidade de origem, vivência que fomenta e alimenta a formação do estudante no que tange à história e à cultura de seu povo. $\mathrm{O}$ tempo-espaço da especialização seguiu três movimentos em sua modulação. Módulo I, denominado "Processos históricos, trajetórias, sujeitos e cultura na educação intercultural indígena”, o qual se constitui de 80 horas-aula presenciais; módulo II, que tratou da Educação, da escola e de suas interfaces, com 150 horas; módulo III, que priorizou a educação de jovens e adultos e a formação profissional nas perspectivas indígena, dedicando a isto 120 horas $^{26}$. Cada um dos módulos constituiu um movimento pedagógico visando colocar em prática a concepção que priorizou o diálogo com os saberes e conhecimentos ameríndios.

Assim, inicialmente se propôs que cada estudante fizesse uma imersão em sua história individual e coletiva. Ao mesmo tempo em que foi proposta a elaboração de um memorial na perspectiva de registrar as histórias de vida e trajetórias educativas, vinculado às expressões simbólicas e às culturas indígenas, também foram desenvolvidos estudos sobre os conhecimentos, saberes e formas educativas dos povos indígenas na América em termos mitológicos, históricos e etnográficos. Nesse módulo foi possibilitado um retorno às origens, aos processos de identificação que constituem os laços de pertencimento de cada pessoa a uma coletividade.

\footnotetext{
${ }^{25}$ Pedagogia da Alternância como processo de formação que acontece em espaços diferenciados e alternados. O primeiro é a comunidade de origem e o segundo, a academia, onde o estudante partilha os diversos saberes que possui com outros atores e reflete sobre eles a partir de propostas acadêmicas.

${ }^{26}$ No anexo I deste texto, detalhamos cada módulo com seus componentes curriculares e as ementas das mesmas.
} 
O segundo módulo abordou a educação, a escola e suas interfaces, voltando as atenções para a história da escolarização e a histórias da educação escolar indígena, aos estudos de currículo, à avaliação, à organização das práticas educativas, à gestão, às políticas educacionais e a questões de metodologia da pesquisa, capacitando cada aluno em particular e os coletivos de pesquisa para realizarem um diagnóstico da educação escolar em suas terras de origem.

No último módulo o enfoque foi a educação escolar na perspectiva indígena, aproximando-se do módulo inicial, em que cada coletivo pensou e elaborou propostas para a escola a partir dos modos de vida, das histórias e das culturas dos povos originários, vislumbrando possibilidades para a educação de jovens e adultos e a formação profissional na perspectiva indígena.

Ao final das aulas presenciais iniciaram-se os trabalhos de conclusão, que estão em fase de elaboração, todos tratando de questões que visam a aproximar as propostas escolares dos saberes e conhecimentos indígenas, pois, como afirmou Andila Nĩvygsãnh Inácio ao apresentar seu trabalho e dizer quais as intenções ao publicar seu estudo dirigido aos seus parentes, quase todo escrito no idioma Kaingang, estes trabalhos precisam ser pensados para

[...] servir de alerta para os professores kaingang que lutam para implementar a escola formal que tenha conhecimento cuja base seja a transmissão dos valores vitais da cultura kaingang, usando as formas próprias de reproduzir conhecimentos. Formas essas que não se aprende em escolas ou universidades, mas voltando as nossas próprias raízes e assoprando as cinzas sob as quais se conservam na memória de nossos anciãos. (INÁCIO, 2010, p. 21).

A docência também foi pensada de modo a favorecer o diálogo e as trocas: os componentes curriculares foram ministrados de forma compartilhada entre professores vinculados à universidade ${ }^{27}$ e professores do povo Kaingang, ou seja, sábios e intelectuais indígenas. Entre estes, destacou-se a participação dos estudantes já formados nas especializações anteriores, mestrandos dos programas de pós-graduação em Educação e História da UFRGS, bem como uma professora, mestre na área de legislação e direitos indígenas, além de sábios da tradição Kaingang. Esse foi um dos aspectos mais importantes do curso, que propiciou de forma mais intensa as interaprendizagens: assim como ocorria a formação dos alunos do curso, formava-se um grupo de professores (da academia e das comunidades indígenas) por meio da docência compartilhada. Em muitas reuniões e encontros de planejamento e avaliação o andamento do curso

\footnotetext{
${ }^{27}$ Participaram do curso professores da Universidade Federal do Rio Grande do Sul (Educação, Antropologia e Letras) e dois professores convidados, da Universidade Federal de Pelotas e da Universidade de Santa Cruz do Sul, ambos com profundo conhecimento dos modos de vida dos povos indígenas. Também participou de forma intensa e propositiva um antropólogo que é gestor do setor de Educação Indígena da Secretaria de Estado da Educação do Rio Grande do Sul.
} 
foi pensado conjuntamente, confluindo e confrontando-se olhares acadêmicos e olhares da tradição ameríndia. A formação docente como um todo teve caráter multidisciplinar, abrangendo as áreas de conhecimento de ciências sociais, história, antropologia, psicologia, educação, letras e direito, bem como conhecimentos tradicionais.

O grupo discente do curso, formado em sua maioria por alunos Kaingang, também é majoritariamente feminino. Entre os estudantes não indígenas havia apenas um estudante do sexo masculino, mas este se desligou do curso ${ }^{28}$, enquanto entre os indígenas a distribuição é equilibrada, $50 \%$ são do sexo feminino e $50 \%$ do masculino. Entre os alunos indígenas os professores da Educação Básica são maioria, mas há também profissionais que atuam no âmbito da saúde, um técnico agrícola, uma pessoa atuante em uma organização não governamental, uma professora que atualmente não leciona e uma bacharela que simultaneamente realiza estudos complementares para a obtenção do título de licenciatura. Em relação aos demais estudantes, há uma professora que atua em uma escola Guarani e duas que atuam em uma escola para jovens em situação de rua que desenvolvem projetos com uma comunidade Kaingang, além de gestoras de políticas públicas e de educação diferenciada. Em relação às áreas de formação, os estudantes indígenas abarcam as áreas de pedagogia, enfermagem, história, geografia, educação física, biologia, filosofia, terapia ocupacional, letras, nutrição, matemática, tecnologia de gestão rural e artes visuais. Entre os não indígenas, as áreas de formação são artes visuais, história, educação física, serviço social, pedagogia e letras.

\section{Um ensaio etnográfico sobre o PROEJA Indígena na UFRGS}

Pela manhã as aulas iniciam às 8 horas. Um pouco antes começam a chegar os estudantes, sendo que os últimos chegam por volta das nove. Aos poucos a turma vai se acomodando e a aula toma seu curso. Há sempre dois ou três alunos que levam chimarrão e compartilham a cuia com os demais. Nas aulas há uma clara divisão espacial entre os estudantes não indígenas e indígenas, divisão que aos poucos foi diminuindo, porém não se dirimiu, sendo que entre os últimos também foi possível perceber uma tendência de as mulheres e os homens formarem grupos distintos.

Embora a relação entre os estudantes seja de cordialidade, observou-se que entre os indígenas alguns são mais cautelosos e reservados na sua relação com os não indígenas, que em sua maioria são mulheres e professoras. De outro lado, alguns alunos não indígenas são bastante participativos em sala de aula e às vezes tendem a inibir as manifestações dos outros estudantes por monopolizarem as falas. Isso aconteceu com muita frequência em momentos em

\footnotetext{
${ }^{28}$ Esse desligamento ocorreu por motivos de trabalho.
} 
que os professores pediam à turma que se manifestasse, quando, geralmente, os alunos não indígenas tomavam a iniciativa de falar. Se por um lado essas pessoas são sensíveis ao universo cultural indígena a ponto de frequentarem um curso de especialização concentrado nessa temática e voltado à formação de especialistas indígenas, por outro, dificilmente priorizam a fala destes. Não obstante, nos indagamos: em que medida o anseio de tomar a palavra não aflora pelo desejo de quebrar o gelo, de começar como forma de abrir o caminho, de possibilitar que os outros falem?

Como espaço de interculturalidade, a sala de aula é palco de tensões e conflitos que em alguns momentos ficam mais evidentes. Um desses momentos aconteceu durante uma aula na qual os alunos deveriam contar narrativas que tinham colhido em suas aldeias de origem. $\mathrm{Na}$ aula debatiam sobre os diferentes tipos de narrativa, entre os quais referiam também as sagradas. Para este trabalho os alunos não indígenas procuraram velhos e lideranças para ouvir e registrar histórias, mas uma das alunas afirmou que só contaria ao professor as histórias que tinha ouvido de uma liderança Kaingang, por não saber o que era ou não sagrado, o que deveria ou não expor na aula. Sua declaração provocou a manifestação de estudantes Kaingang que discordaram do ponto de vista da colega e afirmaram que também queriam ouvir as narrativas, mas ela manteve sua palavra e alguns estudantes ficaram visivelmente irritados com o fato. A preocupação da aluna em não expor indevidamente as narrativas converteu-se para os próprios Kaingang na restrição ao acesso às histórias de seu povo, as quais, contraditoriamente, ficariam apenas entre ela e o professor, aliás, duas pessoas não indígenas.

A particularidade de uma turma com maioria indígena coloca os não indígenas em uma condição incomum e dá espaço a situações que parecem inversões do habitual. Em uma conversa com um aluno Kaingang durante o intervalo de uma aula, ele expressou que as colegas "brancas" haviam comentado que se tinham sentido discriminadas na turma. Ele disse que nunca havia pensado sobre isso, mas que percebeu que também os não indígenas poderiam se sentir discriminados no meio de um grupo majoritariamente indígena. Estava impressionado com a fala das colegas, por outro lado também comentava que essa convivência proporcionada pelo curso constituía uma grande aprendizagem.

Instigadas por esses depoimentos, intuímos que a grande cumplicidade entre os estudantes indígenas, que têm maior intimidade entre si, que se sentam próximos, trocam olhares e às vezes conversam no idioma de seu povo, por si explica um pouco do desconforto, da sensação de exclusão por parte de alunas não indígenas, que são minoria; mas a turma não é feita apenas de diferenças e em vários momentos todos se comportam da mesma forma. Bons exemplos disso são as negociações com os professores para que prorroguem as datas dos trabalhos solicitados e aquelas relativas aos atrasos nas aulas. 
Ao refletirmos sobre as situações aqui narradas, duas palavras se impõem e se entrelaçam em nossas impressões/interpretações: interculturalidade e conflito. De acordo com Nestor Garcia Canclini (2007, p. 17), o exercício e o aprendizado da/na interculturalidade não envolvem apenas compreensões e entendimentos mútuos, mas também conflitos e negociações. Para este autor, falar em interculturalidade não é o mesmo que falar em aceitação do heterogêneo, mas falar de grupos em relações e trocas, que tanto envolvem empréstimos recíprocos quanto conflitos e confrontações. Neste sentido, o curso de especialização se constitui num contexto privilegiado para pensar a complexidade das interações em contextos de interculturalidade.

De outro lado, os conflitos e confrontações na e da interculturalidade também atravessam a subjetividade de cada aluno. Neste sentido, uma aluna relatou que o trabalho de buscar narrativas tradicionais a fizera lembrar-se muito de quando era criança, de quando ouvia seu avô contar histórias e o via fazer benzeduras e falar sobre o uso de muitas ervas. Emocionada, relatou que seu avô falava tudo aquilo e que na época não davam valor ao que ele dizia, e que agora ela estava compreendendo melhor o que ele falava a respeito da importância do conhecimento tradicional. A partir disso, expôs uma contradição vivida entre o fato de ser evangélica, como muitos outros Kaingang e, ao mesmo tempo sentir a importância da valorização dos conhecimentos e do modo de vida tradicional de seu povo. Esta e outras falas aos poucos revelam sentimentos e sentidos que afloram na experiência do curso e também dilemas próprios da experiência indígena em sua relação com a sociedade não indígena. Revelam um pouco da complexidade das posições assumidas por aqueles que precisam articular saberes, valores e práticas da tradição de seu povo e a convivência com referenciais socioculturais de uma cultura dominante e homogeneizadora, a qual, diga-se de passagem, frequentemente vê as pessoas indígenas como "aculturadas", que perderam elementos da cultura tradicional; porém o que colocamos aqui é outra concepção, por acreditarmos que as identidades étnicas não se assentam na "falta da cultura", e sim, numa dinâmica cultural que modifica e também evidencia permanências: há histórias, memórias, problemas e valores compartilhados - não sem conflitos e contradições, é claro - por grupos sociais cuja diferença é invisibilizada.

A contradição em praticar uma religião cristã, cujos valores muitas se opõem às práticas e saberes tradicionais de seu povo, é própria da experiência de muitas pessoas indígenas no estado e em todo o país; mas, se por um lado a presença das igrejas nas aldeias incomoda indígenas e não indígenas na sala de aula, preocupados com o seu impacto cultural nas aldeias, por outro, muitas falas sincretizam saberes e valores tradicionais e cristãos. Neste sentido, ao responder ao comentário de uma aluna que argumentava que as igrejas querem acabar com 
as crenças Kaingang, um professor indígena afirmou que "eles não querem acabar, mas eles não entendem essa outra visão. A bíblia fala das coisas naturais, 'do Kujà', há dois caminhos - espirito santo e demônio - nós escolhemos".

$\mathrm{Na}$ religião, assim como em outras questões, não há um consenso geral entre os estudantes Kaingang. Neste sentido, nos primeiros dias do curso, após o depoimento de um estudante Guarani que afirmou que seu povo valoriza muito o Nhande Reko - modo próprio de ser Guarani - e que não dá muita importância para as coisas materiais, que são mais fechados para a sociedade capitalista, um estudante Kaingang afirmou que seu povo também preserva muito a sua tradição; mas complementou dizendo que também é importante a modernização, para fazerem frente à competição no capitalismo. Disse que da maneira como os Kaingang vivem hoje, estão 50 anos atrasados, e que ele não quer viver atrasado, quer competir no capitalismo. Em outra direção, a partir de uma discussão sobre os conhecimentos da tradição e a educação escolar, ao tecer uma crítica sobre a sociedade não indígena, uma aluna anuncia os perigos da proximidade com esse modo de ser que é diferente do indígena. Nas suas palavras, "os brancos consideram crime a menina casar com 13 anos, depois que menstrua. E colocar os velhos no asilo? Para nós, isso é crime. Se nós não cuidarmos nossa cabeça, daqui a pouco estamos pensando que nem eles".

Algumas discussões expressam contradições e modos diferentes de pensar, mesmo entre os próprios Kaingang; no entanto, apesar das diferenças de pensamento e de entendimento em relação às estratégias a serem adotadas, a preocupação com a continuidade e o bem-estar de seu povo no futuro é um horizonte comum para todos os estudantes indígenas na sala de aula. A partir do relato de algumas observações sobressai o caráter pedagógico da convivência intra e interétnica proporcionada pelo curso, evidenciando a riqueza de sua proposta pedagógica e curricular e a forma como é praticada nas aulas. Ao possibilitar que estudantes indígenas e não indígenas estejam juntos, a escola passa a ser um espaço também de articulação, disputa e de pensar coletivo sobre a complexidade da experiência indígena e seus desafios no campo da educação, como em muitos outros domínios. É um contexto que por si só é capaz de proporcionar experiências e aprendizagens muito valiosas para alunos e professores, indígenas e não indígenas. Dito de outro modo, não há como um curso com essa configuração não ser diferenciado, apesar de compartilhar uma estrutura normativa comum com os demais cursos em nível de especialização no país.

\section{Conquistas e desafios a partir da proposta de formação intercultural}

O curso coloca algumas questões importantes para pensar a formação de professores indígenas: se, como os povos originários, almejamos uma escola 
intercultural, situada na fronteira, na região que aproxima dois mundos, dois modos de vida com fortes diferenças, mas com humanas identificações, como formar professores apenas pelo viés da academia? De outro lado, como não reconhecer a riqueza proporcionada pelo trabalho conjunto e pela convivência entre professores e alunos, indígenas e não indígenas no contexto de uma proposta diferenciada? Acreditamos que a primeira conquista diz respeito à realização do curso específico e diferenciado, embora ainda com o predomínio de uma metodologia clássica da academia, a qual, mesmo reconhecendo teoricamente o valor da oralidade, na prática está centrada na escrita.

Outro ponto que se destaca como conquista diz respeito à docência compartilhada entre professores indígenas e não indígenas, sendo que ambos os segmentos - o indígena e o acadêmico - atuam mediando e intermediando saberes. Há, nessa prática, uma dupla formação de professores, visto que ao se partilhar o espaço da docência a aprendizagem é recíproca; e não podemos deixar de mencionar nessa prática o reconhecimento, por parte da academia, dos saberes indígenas.

Ademais, apesar de um projeto que pouco interfere na institucionalidade universitária ainda monocromática, a aposta é que se abra uma porta de fluxo contínuo para o diálogo, possibilitando fazeres conjuntos, mesmo considerando a conflitualidade que caracteriza essa vivência. Canclini (2007, p. 17) diz que para existir a interculturalidade é necessária a vontade de compreender, reconhecer e admitir que todos os grupos culturais se constituem em relação, sugerindo "negociação, conflito e empréstimos recíprocos". Acrescenta que interculturalidade, enquanto relação entre culturas, só pode ser pensada ao se conceber que a cultura abarca processos sociais de significação, ou seja, "processos sociais de produção, circulação e consumo da significação na vida social" (CANCLINI, 2007, p. 41), o que, no nosso entender, teria a potência de transformar ambos os envolvidos.

O formato do curso, não obstante estar organizado temporalmente como pedagogia da alternância - tempo-escola; tempo-comunidade -, enquadrou os alunos nos tempos escolares convencionais, com seus prazos e seus horários extremamente controlados. O espaço da universidade também foi o cenário majoritário do curso e, conquanto essa "ocupação" contribua para alterar a paisagem e "indianizar" os ambientes universitários, representando a realização do sonho de muitos estudantes indígenas que almejavam estudar na UFRGS, funciona igualmente como situação que os distancia e afasta dos territórios originários. Também saímos do espaço eminentemente acadêmico para apresentar aos estudantes algumas atrações da cidade: a $8^{a}$ Bienal de Artes visuais do MERCOSUL, Museu Iberê Camargo, Usina do Gasômetro, visitas realizadas com respeito e admiração por cada um dos participantes do curso. Tivemos ainda uma aula na 
aldeia Kaingang Fág Nhin, Lomba do Pinheiro, Porto Alegre, RS. De qualquer forma, fica o desafio de construir um espaço compartilhado, deslocando-se a universidade para os viveres de uma terra indígena, e de dispor-se, por exemplo, a habitar outras línguas, pois, mesmo sendo estudantes de um só povo, a língua kaingang não foi priorizada.

Por fim, a partir dessas reflexões iniciais, temos clareza de quanto ainda precisamos caminhar juntos, indígenas e não indígenas, para alcançar uma proposta de formação de professores eminentemente intercultural; porém, temos também lucidez para reconhecer os avanços proporcionados pelo curso no caminho de uma educação intercultural.

\section{Referências}

AMANCIO, C. N. Educação escolar em comunidades indígenas kanhgág da bacia do Tibagi. In: CONGRESSO BRASILEIRO DE ETNOMATEMÁTICA, 1., 2000, São Paulo. Anais... São Paulo: USP, 2000. Disponível em: <http://www2.fe.usp.br/ etnomat/site-antigo/ anais/Chateaubriand.html>. Acesso em: 13 maio 2008.

BALANDIER, G. O contorno: poder e modernidade. Rio de Janeiro: Bertrand Brasil, 1997. BANIWA, G.; HOFFMANN, M. B. Introdução. In: LUCIANO, G. J. dos S.; OLIVEIRA, J. C. de.; HOFFMANN, M. B. Olhares indígenas contemporâneos. Brasília: Centro Indígena de Pesquisas, 2010. p. 6-17.

BELFORT, A. I. A formação dos primeiros professores indígenas no Sul do Brasil. Cadernos de Educação Escolar Indígena - $3^{\circ}$ Grau Indígena, Barra do Bugres: UNEMAT, Cáceres, v. 4, n. 1, p. 9-20, 2005.

BergamasCHI, M. A. Nhembo'e. Enquanto o encanto permanece! Processos e práticas de escolarização nas aldeias Guarani. 2005. 270 f. Tese (Doutorado em Educação) - Universidade Federal do Rio Grande do Sul, Faculdade de Educação, Porto Alegre, 2005.

BERGAMASCHI, M. A.; VENZON, R. A. (Org.). Pensando a educação kaingang. Pelotas: Editora Universitária/UFPel, 2010.

BRASIL. Decreto no 8.072, de 20 de junho de 1910. Crêa o Serviço de Protecção aos Indios e Localização de Trabalhadores Nacionaes e approva o respectivo regulamento. Diário Oficial da União, Brasília, 24 jun. 1910. Seção 1. p. 4788.

. Lei $\mathrm{n}^{\circ}$ 5.371, de 05 de dezembro de 1967. Autoriza a instituição da "Fundação Nacional do Índio" e dá outras providências. Diário Oficial da União, Brasília, 06 dez. 1967. . Lei no 6.001, de 19 de dezembro de 1973. Dispõe sobre o Estatuto do Índio. Diário Oficial da União, Brasília, 21 dez. 1973.

. Constituição (1988). Constituição da República Federativa do Brasil. Brasília, 05 out. 1988 . 
Ministério da Educação. Portaria Interministerial no 559, de 16 de abril de 1991. Dispõe sobre a Educação Escolar para as Populações Indígenas. Diário Oficial da União, Brasília, 17 abr. 1991a. Seção 1. p. 7.084.

. Lei no 9.493, de 20 de dezembro de 1996. Estabelece as diretrizes e bases da educação nacional. Diário Oficial da União, Brasília, 20 dez. 1996.

Ministério da Educação. Instituto Nacional de Estudos e Pesquisas Educacionais. Diretrizes para a Política Nacional de Educação Escolar Indígena. Em Aberto, Brasília, ano 14, n. 63, p. 175-187, jul./set. 1994.

Ministério da Educação. Resolução CEB nº 03, de 10 de novembro de 1999. Fixa Diretrizes Nacionais para o funcionamento das escolas indígenas e dá outras providências. Diário Oficial da União, Brasília, 17 nov. 1999. Seção 1. p. 19.

- Ministério da Educação. Instituto Nacional de Estudos e Pesquisas Educacionais. Censo Escolar Indígena - 1999. Brasília, 2001.

. Ministério da Educação. Instituto Nacional de Estudos e Pesquisas Educacionais. Estatísticas sobre Educação Escolar Indígena no Brasil. Brasília, 2007.

Ministério da Educação. Secretaria de Educação Profissional e Tecnológica. Universidade Federal do Rio Grande do Sul. Dispõe sobre o Processo de Seleção do Curso de Pós-Graduação Lato Sensu - Especialização em Educação Profissional Integrada à Educação Básica na Modalidade Educação de Jovens e Adultos - proposta diferenciada indígena. Porto Alegre, 05 nov. 2010.

. Ministério Público Federal. MPF/RS quer a instalação de escola de professores indígenas (Notícias). Disponível em: <www.noticias.pgr.mpf.gov.br/noticias/noticiasdo-site/copy-of-indios-e-minorias/mpf-rs-quer-instalacao-de-escola-de-formacao-deprofessores-indigenas>. Acesso em: 08 jun. 2011.

CANCLINI, N. G. Diferentes, desiguais e desconectados. Rio de Janeiro: Ed. UFRJ, 2007.

CLAUDINO, Z. K. Educação Indígena em diálogo. Pelotas: Editora Universitária/ UFPel, 2010.

COLLET, C. L. G. Interculturalidade e educação escolar indígena: um breve histórico. Cadernos de Educação Escolar Indígena - $3^{\circ}$ Grau Indígena, Barra do Bugres: UNEMAT, Cáceres, v. 2, n. 1, p. 173-188, 2003.

DORNELES, M. do A. Disposições ético-estético-afetivas e desafios teórico-metodológicos na pesquisa em educação. In: REUNIÃO ANUAL DA ANPED, 26., 2003, Poços de Caldas. Anais... Poços de Caldas: ANPED, 2003. Disponível em: <http://www.anped.org.br/ reunioes/26/inicio.htm>. Acesso em: 22 set. 2011.

FIDENE - Fundação Integração, Desenvolvimento e Educação do Noroeste do Estado. UNIJUÍ - Universidade Regional do Noroeste do Estado do Rio Grande do Sul. FUPF Fundação Universidade de Passo Fundo. FUNAI - Fundação Nacional do Índio. Projeto Vãfy (Artesanato). Ijuí; Passo Fundo, 2001.

INÁCIO, A. N. Vẽnh Kanhrãn. In: BERGAMASCHI, M. A.; VENZON, R. A. (Orgs.). Pensando a Educação kaingang. Pelotas: Editora Universitária/UFPel, 2010. p. 8-28. 
INSTITUTO BRASILEIRO DE GEOGRAFIA E ESTATÍSTICA. Os indígenas no Censo Demográfico 2010 - primeiras considerações com base no quesito cor ou raça. Rio de Janeiro, 2012.

PROEJA INDÍGENA. Especialização em Educação Profissional Integrada à Educação Básica na Modalidade Educação de Jovens e Adultos. Proposta diferenciada para indígenas. [20--].

PROJETO POLÍTICO PEDAGÓGICO. Programa de Formação para a Educação Escolar Guarani na Região Sul e Sudeste do Brasil - Kuaa Mbo'e - Conhecer-Ensinar. Ago. 2003.

RIO GRANDE DO SUL. Secretaria Estadual de Educação. Departamento Pedagógico. Divisão de Ensino Fundamental. Divisão de Estrutura e Funcionamento Escolar. Quadro de dados das Escolas Indígenas no RS, 2000.

Secretaria da Educação. Departamento Pedagógico. Of-Circ./GAB/DP/nº 39/01, de 03 de julho de 2001.

Secretaria da Educação. Departamento Pedagógico. Banco de Dados das Escolas Indígenas, 2002a.

. Secretaria da Educação. Dados sobre a Regularização das Escolas Indígenas, dezembro de 2002b.

ROLNIK, S. Cartografia Sentimental: transformações contemporâneas do desejo. São Paulo: Estação Liberdade, 1989.

UNIVERSIDADE FEDERAL DO RIO GRANDE DO SUL. Conselho Universitário. Decisão $\mathbf{n}^{\mathbf{0}}$ 134/2007. Leis, Porto Alegre, 29 jun. 2007.

UNIJUÍ - Universidade Regional do Noroeste do Estado do Rio Grande do Sul. FIDENE - Fundação Integração, Desenvolvimento e Educação do Noroeste do Estado. Plano de Curso Supletivo em Nível de Ensino Médio de $2^{\circ}$ Grau - Habilitação Magistério para a Formação de Professores Indígenas Bilíngues. Ijuí, 1997.

\section{Anexo}

ESTRUTURA CURRICULAR DO CURSO

\begin{tabular}{|c|c|c|}
\hline \multicolumn{3}{|c|}{$\begin{array}{c}\text { Módulo I: } \\
\text { PROCESSOS HISTÓRICOS, TRAJETÓRIAS, SUJEITOS E CULTURAS INDÍGENAS }\end{array}$} \\
\hline $\begin{array}{l}\text { Componente } \\
\text { Curricular }\end{array}$ & Ementa & $\begin{array}{l}\text { Carga } \\
\text { horária }\end{array}$ \\
\hline $\begin{array}{l}\text { Histórias de Vida e } \\
\text { Trajetórias Educativas: } \\
\text { expressões simbólicas e } \\
\text { culturas indígenas }\end{array}$ & $\begin{array}{l}\text { O educador indígena em seu percurso de vida/educacional/ } \\
\text { de aprendizagem relacionado aos processos educativos } \\
\text { escolares e não escolares em sua comunidade. Significado } \\
\text { simbólico dos ritos e mitos na construção das identidades } \\
\text { ameríndias através da arte e da expressão corporal. O caráter } \\
\text { poético e ficcional nas produções orais e escritas. Corpo e } \\
\text { voz nas performances. }\end{array}$ & $60 \mathrm{~h}$ \\
\hline
\end{tabular}




\begin{tabular}{|c|c|c|}
\hline $\begin{array}{l}\text { Educação Tradicional } \\
\text { nas perspectivas indí- } \\
\text { genas }\end{array}$ & $\begin{array}{l}\text { Estudo sobre os conhecimentos, saberes e formas educativas } \\
\text { dos povos indígenas na América em termos mitológicos, } \\
\text { históricos e etnográficos. Contemporaneidade dessas formas } \\
\text { de educação tradicional concomitantes à educação escolar. }\end{array}$ & $30 \mathrm{~h}$ \\
\hline \multicolumn{3}{|c|}{ PRODUÇÃO INDIVIDUAL DO MÓDULO: Memoriais } \\
\hline \multicolumn{3}{|c|}{$\begin{array}{c}\text { Módulo II: } \\
\text { EDUCAÇÃO, ESCOLA E SUAS INTERFACES }\end{array}$} \\
\hline $\begin{array}{l}\text { História da escolariza- } \\
\text { ção no Brasil e histórias } \\
\text { da educação escolar in- } \\
\text { dígena }\end{array}$ & $\begin{array}{l}\text { Estudo sobre a produção e a reprodução da escola no Brasil, } \\
\text { compreensão das principais visões pedagógicas e práticas } \\
\text { educativas desenvolvidas no Brasil desde a colonização até a } \\
\text { atualidade com ênfase na Educação Indígena, EJA, Educação } \\
\text { Profissional e Ensino Médio. }\end{array}$ & $30 \mathrm{~h}$ \\
\hline $\begin{array}{l}\text { Educação de Jovens e } \\
\text { Adultos e educação e } \\
\text { trabalho: práticas esco- } \\
\text { lares e não escolares }\end{array}$ & $\begin{array}{l}\text { Políticas educacionais e suas interfaces na educação de jovens } \\
\text { e adultos, ensino médio e na educação profissional e educação } \\
\text { especial: sentidos, concepções histórico-pedagógicas no } \\
\text { Brasil. }\end{array}$ & $30 \mathrm{~h}$ \\
\hline $\begin{array}{l}\text { Currículo, avaliação, or- } \\
\text { ganização das práticas } \\
\text { educativas, gestão e po- } \\
\text { líticas educacionais }\end{array}$ & $\begin{array}{l}\text { Análises teórico-conceituais em torno da temática do } \\
\text { currículo destacando o tema da avaliação como ingrediente } \\
\text { da construção curricular e aperfeiçoamento do processo } \\
\text { de ensino com ênfase nas peculiaridades da EJA integrada } \\
\text { ao ensino profissional na especificidade indígena. Políticas, } \\
\text { gestão, organização e legislação no âmbito da educação } \\
\text { escolar específica e diferenciada. }\end{array}$ & $30 \mathrm{~h}$ \\
\hline $\begin{array}{l}\text { Metodologia da } \\
\text { Pesquisa }\end{array}$ & $\begin{array}{l}\text { A construção do objeto de pesquisa em Educação: } \\
\text { motivações, delimitação do problema de pesquisa, } \\
\text { delineamento teórico a partir das especificidades indígenas. } \\
\text { Desenvolvimento da metodologia que embasa a investigação } \\
\text { qualitativa: os paradigmas e as técnicas que a sustentam, } \\
\text { enfatizando o trabalho de campo através da observação } \\
\text { participante, estudos de caso, histórias de vida, entrevistas } \\
\text { abertas e semi-dirigidas. }\end{array}$ & $30 \mathrm{~h}$ \\
\hline $\begin{array}{l}\text { Legislação e direitos } \\
\text { específicos indígenas }\end{array}$ & $\begin{array}{l}\text { Emergência das cidadanias de indígenas a partir de processos } \\
\text { organizativos onde o plano educacional é um de seus } \\
\text { principais campos de luta pela garantia de direitos. Introdução } \\
\text { à antropologia, etnocentrismo e diversidade cultural. Debates } \\
\text { contemporâneos sobre mídia e comunidades tradicionais; } \\
\text { autêntico e inautêntico nas identidades étnico-raciais }\end{array}$ & $30 \mathrm{~h}$ \\
\hline
\end{tabular}




\begin{tabular}{|c|c|c|}
\hline \multicolumn{3}{|c|}{$\begin{array}{c}\text { PRODUÇÃO COLETIVA DO MÓDULO: Diagnóstico da Educação Escolar Indígena no } \\
\text { RS }\end{array}$} \\
\hline \multicolumn{3}{|c|}{$\begin{array}{c}\text { Módulo III: } \\
\text { EDUCAÇÃO DE JOVENS E ADULTOS E FORMAÇÃO PROFISSIONAL NA } \\
\text { PERSPECTIVA INDÍGENA }\end{array}$} \\
\hline $\begin{array}{l}\text { Métodos Próprios de } \\
\text { Aprendizagem }\end{array}$ & $\begin{array}{l}\text { Culturas indígenas, seus saberes e formas de aprendizagem } \\
\text { atualizadas nos contextos de escolarização. Proposta de } \\
\text { educação escolar tendo como base a tradição, os saberes } \\
\text { ancestrais e o modo de vida das aldeias indígenas na } \\
\text { composição dos componentes curriculares (tanto na forma } \\
\text { como no conteúdo) }\end{array}$ & $60 \mathrm{~h}$ \\
\hline $\begin{array}{l}\text { Projeto Político } \\
\text { Pedagógico: PROEJA } \\
\text { Indígena. }\end{array}$ & $\begin{array}{l}\text { Discute as referências organizativas da educação escolar } \\
\text { buscando formatá-la a partir de referenciais, cultura, formas } \\
\text { educativas, e interesses coletivos de povos indígenas: EJA } \\
\text { na estrutura educacional brasileira; currículo de EJA e } \\
\text { suas possibilidades, significado e aprendizagem. PROEJA: } \\
\text { articulação entre projeto de sociedade e projeto educacional; } \\
\text { organização dos tempos e espaços pedagógicos. }\end{array}$ & $60 \mathrm{~h}$ \\
\hline \multicolumn{3}{|c|}{$\begin{array}{c}\text { PRODUÇÃO COLETIVA DO MÓDULO: Pressupostos para embasar o projeto de Ensino } \\
\text { Médio Indígena }\end{array}$} \\
\hline
\end{tabular}

Recebido em 17/05/2012

Versão final recebida em 06/09/2012

Aceito em 30/10/2012 